\title{
Re-evaluating the treatment of acute optic neuritis
}

\section{OPEN ACCESS}

\author{
Jeffrey L Bennett, ${ }^{1}$ Molly Nickerson, ${ }^{2}$ Fiona Costello, ${ }^{3}$ Robert C Sergott, ${ }^{4}$ \\ Jonathan C Calkwood, ${ }^{5}$ Steven L Galetta, ${ }^{6}$ Laura J Balcer, ${ }^{6}$ Clyde E Markowitz, ${ }^{7}$ \\ Timothy Vartanian, ${ }^{8}$ Mark Morrow, ${ }^{9}$ Mark L Moster, ${ }^{4}$ Andrew W Taylor, ${ }^{10}$ \\ Thaddeus W W Pace, ${ }^{11}$ Teresa Frohman, ${ }^{12}$ Elliot M Frohman ${ }^{12,13}$
}

For numbered affiliations see end of article.

\section{Correspondence to Dr Elliot M Frohman, Department of Neurology and Neurotherapeutics, University of Texas Southwestern Medical Center at Dallas, 5323 Harry Hines Blvd., Dallas, Texas \\ 75235, USA; \\ elliot.frohman@ \\ utsouthwestern.edu}

Received 27 March 2014 Revised 5 August 2014 Accepted 28 September 2014 Published Online First 29 October 2014

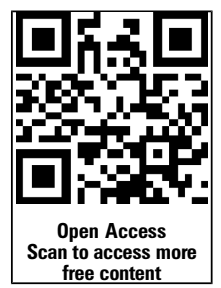

CrossMark

To cite: Bennett JL, Nickerson M, Costello F, et al. I Neurol Neurosurg Psychiatry 2015;86: 799-808.

\section{ABSTRACT}

Clinical case reports and prospective trials have demonstrated a reproducible benefit of hypothalamicpituitary-adrenal (HPA) axis modulation on the rate of recovery from acute inflammatory central nervous system (CNS) demyelination. As a result, corticosteroid preparations and adrenocorticotrophic hormones are the current mainstays of therapy for the treatment of acute optic neuritis (AON) and acute demyelination in multiple sclerosis.

Despite facilitating the pace of recovery, HPA axis modulation and corticosteroids have failed to demonstrate long-term benefit on functional recovery. After AON, patients frequently report visual problems, motion perception difficulties and abnormal depth perception despite 'normal' (20/20) vision. In light of this disparity, the efficacy of these and other therapies for acute demyelination require re-evaluation using modern, high-precision paraclinical tools capable of monitoring tissue injury.

In no arena is this more amenable than $A O N$, where a new array of tools in retinal imaging and electrophysiology has advanced our ability to measure the anatomic and functional consequences of optic nerve injury. As a result, AON provides a unique clinical model for evaluating the treatment response of the derivative elements of acute inflammatory CNS injury: demyelination, axonal injury and neuronal degeneration.

In this article, we examine current thinking on the mechanisms of immune injury in AON, discuss novel technologies for the assessment of optic nerve structure and function, and assess current and future treatment modalities. The primary aim is to develop a framework for rigorously evaluating interventions in AON and to assess their ability to preserve tissue architecture, reestablish normal physiology and restore optimal neurological function.

\section{CURRENT TREATMENT OF ACUTE OPTIC NEURITIS \\ Corticosteroids}

In 1961, Miller and colleagues demonstrated that patients with multiple sclerosis (MS), who were treated with corticotrophin recovered more quickly and completely from acute relapses than did patients treated with saline. ${ }^{1}$ A subsequent study of acute optic neuritis (AON) by Rawson and Liversedge $^{2}$ demonstrated that a similar hastening of visual recovery was noted after acute retrobulbar neuritis; however, no significant difference between visual outcomes could be determined 12 months after the inception of visual symptoms. The emergence of intravenous methylprednisolone for the treatment of a range of immune-mediated disorders prompted its application for the treatment of acute MS exacerbations, including AON, whereby early benefits were noted regarding the course of clinical recovery. ${ }^{3}$

In 1992, the Optic Neuritis Treatment Trial (ONTT) provided the first comprehensive examination of the benefits of steroid therapy for $\mathrm{AON}$ in a large and representative patient cohort. In the ONTT, patients were randomised to receive placebo, oral (low-dose) prednisone $(1 \mathrm{mg} / \mathrm{kg} / \mathrm{day}$ for 14 days) or high-dose intravenous methylprednisolone (250 mg 4 times daily for 3 days), followed by oral prednisone $(1 \mathrm{mg} / \mathrm{kg} /$ day for 11 days). At 6 months, colour vision and contrast sensitivity significantly improved in the methylprednisolone $\mathrm{arm}^{4}$; however, after 1 year, there was no significant difference between treated and untreated patients in any functional outcomes. ${ }^{5}$ Intravenous methylprednisolone was found to accelerate the rate of visual recovery over the first 15 days. ${ }^{4}$ Objective measures of optic nerve or retinal architecture were not available at the time of the ONTT; however, a subsequent study showed no effect of corticosteroids on optic nerve atrophy. ${ }^{6}$

In a subsequent analysis, patients randomised to receive treatment with high-dose intravenous methylprednisolone in conjunction with 11-day low-dose oral prednisone taper exhibited a significantly reduced risk of developing clinically definite MS (defined by the development of a second bona fide inflammatory demyelinating syndrome) over the subsequent 2 years. ${ }^{7}$ Notwithstanding this apparently noteworthy outcome, no significant disease-modifying effects were confirmed beyond the second year of ascertainment. Although the data from the ONTT have been reviewed rigorously, some have questioned the finding that intravenous steroids may produce a short-term benefit in delaying the onset of MS and that the risk of recurrent optic neuritis increases with the use of oral prednisone alone. ${ }^{8}$ Concerns include the lack of treatment blinding, post hoc analyses, small sample sizes, recoding of patient classifications and changes in the statistical assumptions. Despite the wealth of data gathered in the ONTT, critical questions regarding patient management remain unanswered. These include the following: (1) whether corticosteroid treatment is beneficial in patients whose symptom duration is longer than 
8 days; (2) whether higher doses of corticosteroids are more effective than lower doses; (3) what is the optimal corticosteroid regimen; (4) whether the observed increased ON recurrence rate associated with oral prednisone also is observed in MS attacks and (5) whether high-dose methylprednisolone given periodically will improve the prognosis for patients with MS.

\section{Intravenous immunoglobulin and plasma exchange}

Intravenous immunoglobulin (IVIg) and plasma exchange (PLEX) also have been studied for the treatment of AON. Roed et $a l^{9}$ found no effect of IVIg on long-term visual function or on the latency of visual evoked potential (VEP) responses after AON. Further, IVIg did not improve visual function in patients with persistent vision loss after AON. ${ }^{10}$ Alternately, PLEX has demonstrated efficacy in the treatment of refractory $\mathrm{AON}^{11}$ and AON associated with neuromyelitis optica (NMO). ${ }^{12}$ Ruprecht et $a l^{11}$ observed a significant improvement in visual recovery following the institution of PLEX in cases of refractory AON; however, the rapid use of PLEX in this study may have masked any delayed benefit still to be derived from initial treatment with intravenous methylprednisolone. In fact, the authors noted that there is significant variability in the magnitude and tempo of efficacy derived from corticosteroid use among patients with AON. Indeed, a similar degree of variability can be observed in patients who derive clinical benefits from PLEX, either in isolation or following corticosteroid treatment.

A recent study evaluating the addition of PLEX to intravenous methylprednisolone in the acute treatment of NMO-associated AON showed significant improvements in high-contrast acuity, visual fields and temporal retinal nerve fibre layer (RNFL) thickness, ${ }^{12}$ but not low-contrast letter scores or colour vision. The early, first-line use of PLEX in the treatment of AON, however, has yet to be evaluated.

\section{Erythropoietin}

Systemic infusion of erythropoietin with and without methylprednisolone has demonstrated beneficial effects on retinal ganglion cell (RGC) function and survival in a rat model of experimental autoimmune encephalomyelitis. ${ }^{13}$ Erythropoietin administration increased protein levels of phospho-Akt, phospho-MAPK 1 and 2 and Bcl-2, indicating that activation of the Akt signalling pathway may be critical for limiting RGC apoptosis after AON. In combination with methylprednisolone, erythropoietin led to partial recovery of pattern-reversal VEPs and significantly improved flash electroretinograms (ERGs). ${ }^{13}$ Recently, a phase 2 clinical trial compared systemic erythropoietin with placebo in the treatment of $\mathrm{AON}$ in a small cohort of patients. ${ }^{14}$ Treatment with erythropoietin resulted in significant improvement in the average thickness of the peripapillary RNFL (as measured by optical coherence tomography (OCT)) and improved VEP latencies at week 16. Mean visual acuity showed a trend towards improvement after erythropoietin treatment. Given the inherent variability of optic nerve electrophysiology, the limitations of time-domain OCT, and the small study size, the paraclinical benefits observed with erythropoietin treatment will need to be confirmed in a multicentre prospective investigation.

\section{Why a renewed focus on optic neuritis?}

Novel technologies and an improved understanding of neuroinflammation have provided an ideal environment for renewed investigations into the early treatment for $\mathrm{AON}$ (table 1). Spectral domain OCT, scanning laser polarimetry (SLP), diffusion tensor imaging (DTI), multifocal VEPs (mfVEP) and the optic nerve head component (ONHC) of the multifocal ERG (mfERG) represent technical advancements in our ability to characterise precisely and objectively the complex architecture of the retina and optic nerve and correlate structural integrity with corresponding functional measures of visual system physiology. ${ }^{15-22}$ The application of these new tools to the investigation of structure-function derangements in AON will validate using the eye as a surrogate for studying the various mechanisms of central nervous system (CNS) injury in MS and provide a clinical paradigm to assay the potential neuroprotective and neurorestorative effects of therapeutic agents. These contentions have already been partly corroborated by a number of recent investigations that have provided seminal insights into the pathobiological underpinnings that drive structural and functional derangements in the visual system of patients with MS.

\section{OCT/scanning laser polarimetry}

OCT and SLP are optical imaging modalities that can measure the RNFL thickness. Already, multiple investigations have confirmed that both OCT and SLP have the capability to confirm significant thinning of this inner retinal layer composed of RGC axons and glial tubules formed by Muller cell processes. The RNFL axons are unmyelinated and derived from the ganglion cells of the macular retina, which become organised at the neural-retinal rim (the tissue between the papilla of the optic disc and the edge of the optic cup), beyond which point they are consolidated as the optic nerve (composed of about 1-1.2 million axons). As the optic nerve axons traverse the lamina cribrosa, they acquire myelin derived from CNS oligodendrocytes, with their corresponding electrical transmission properties transforming from slow membrane to highly rapid, saltatory conduction. $^{17}$

OCT measures the interference spectrum of infrared light that has penetrated through the retina using a spectrometer and highspeed linescan camera. In spectral domain OCT, the 'backscattered' spectrum is Fourier transformed to obtain the magnitude and echo time delay of the light, thereby producing a set of axial images for analysis. ${ }^{23}$ Alternatively, SLP is an imaging technique that utilises the polarising birefringence properties of the RNFL to determine thickness of the retinal layers. ${ }^{24}$ The principal compositional element thought to contribute to RNFL birefringence is the intra-axonal microtubule. Because the SLP-derived RNFL thickness is calculated using the phase shift of polarised light, compensation for corneal birefringence is required and may be problematic in some individuals. ${ }^{24}$

Owing to their distinct technologies, OCT and SLP demonstrate RNFL oedema and thinning with varying efficacy. Specifically, OCT shows RNFL swelling (as water influences infrared light backscatter in OCT, whereas oedema is invisible to SLP because water is not a birefringent medium) better than SLP. $^{25}$ Both technologies, however, appear equally efficient in measuring RNFL loss after acute inflammatory injury. Alternately, determining the true baseline RNFL thickness measure early in AON may be more accurate when utilising SLP, given that thickness measures are confounded by oedema in OCT. Despite the potential limitations of OCT in the acute setting of AON, the advent of high-precision retinal segmentation with spectral domain OCT (see below) has elucidated exciting data that suggest that detailed retinal analysis can yield baseline thickness measures that are not influenced by RNFL oedema and provide a 'true' baseline measure for the longitudinal analysis of putative neuroprotective therapeutic agents. ${ }^{22}$

The introduction of SLP and OCT in the eye clinic has greatly enhanced the appreciation for the timing and extent of 
Table 1 Investigations into the early treatment for AON

\begin{tabular}{|c|c|c|c|c|}
\hline Intervention & Participants & Outcome & Side effects & Reference \\
\hline $\begin{array}{l}\text { ACTH } 40 \text { IU/day } \times 30 \text { days }(n=25) \\
\text { Placebo }(n=25)\end{array}$ & $\begin{array}{l}50 \text { patients with acute retrobulbar } \\
\text { neuritis }\end{array}$ & $\begin{array}{l}\text { Patients treated with ACTH recovered 'more } \\
\text { quickly and more completely' (high-contrast } \\
\text { visual acuity) }\end{array}$ & Facial or ankle oedema & 69 \\
\hline $\begin{array}{l}\text { ACTH } 40 \text { IU/day } \times 30 \text { days }(n=27) \\
\text { Placebo }(n=27)\end{array}$ & $\begin{array}{l}54 \text { patients with acute optic neuritis } \\
\text { ( } 4 \text { patients with MS in ACTH group } \\
\text { and } 5 \text { in placebo group) }\end{array}$ & $\begin{array}{l}\text { No differences in high-contrast visual acuity, } \\
\text { visual field, macular threshold or colour vision }\end{array}$ & $\begin{array}{l}\text { Weight gain, facial oedema, } \\
\text { ankle oedema, acne, depression, } \\
\text { rash }\end{array}$ & 70 \\
\hline $\begin{array}{l}\text { EPO } 33000 \mathrm{IU} / \text { day } \times 3 \text { days } \\
+ \text { IVMP } 1000 \mathrm{mg} / \text { day } \times 3 \text { days } \\
(\mathrm{n}=21) \\
\text { Placebo+IVMP } \\
1000 \mathrm{mg} / \text { day } \times 3 \text { days }(\mathrm{n}=19)\end{array}$ & $\begin{array}{l}40 \text { patients with first episode optic } \\
\text { neuritis }\end{array}$ & $\begin{array}{l}\text { EPO-treated patients had less RNFL thinning, } \\
\text { smaller reduction in retrobulbar diameter of } \\
\text { optic nerve and shorter VEP latencies; } \\
\text { differences in visual function did not reach } \\
\text { significance }\end{array}$ & $\begin{array}{l}\text { IVMP_-hot flashes, facial } \\
\text { flushing, mood changes and } \\
\text { hyperglycaemia attributed to } \\
\text { IVMP } \\
\text { EPO-headache }\end{array}$ & 14 \\
\hline $\begin{array}{l}\text { IVMP } 1000 \mathrm{mg} / \mathrm{day} \times 3 \text { days+oral } \\
\text { prednisone } 1 \mathrm{mg} / \mathrm{kg} \times 11 \text { days } \\
(\mathrm{n}=151) \\
\text { Oral prednisone } 1 \mathrm{mg} / \\
\mathrm{kg} \times 14 \text { days }(\mathrm{n}=156) \\
\text { Placebo }(\mathrm{n}=150)\end{array}$ & $\begin{array}{l}457 \text { patients with acute optic } \\
\text { neuritis across } 15 \text { clinical centres }\end{array}$ & $\begin{array}{l}\text { The group receiving IVMP recovered visual } \\
\text { function faster than the group receiving oral } \\
\text { prednisone only; at } 6 \text { months the IVMP group } \\
\text { had better contrast sensitivity, colour vision, a } \\
\text { trend towards better visual field, but not } \\
\text { better visual acuity }\end{array}$ & $\begin{array}{l}\text { IVMP_transient depression, } \\
\text { acute pancreatitis } \\
\text { IVMP, prednisone-sleep } \\
\text { disturbance, mild mood change, } \\
\text { stomach upset and facial flushing }\end{array}$ & 4 \\
\hline $\begin{array}{l}\text { IVMP } 1000 \mathrm{mg} / \text { day } \times 3 \text { days } \\
(\mathrm{n}=33) \\
\text { Placebo }(\mathrm{n}=33)\end{array}$ & $\begin{array}{l}66 \text { patients with first episode acute } \\
\text { unilateral optic neuritis }\end{array}$ & $\begin{array}{l}\text { Optic nerve atrophy at } 6 \text { months was similar } \\
\text { for placebo and IVMP-treated groups } \\
\text { IVMP did not improve visual outcomes or } \\
\text { lesion length }\end{array}$ & Not reported & 671 \\
\hline $\begin{array}{l}\text { Plasma exchange } \times 5 \text { cycles } \\
(n=23)\end{array}$ & $\begin{array}{l}10 \text { patients with RRMS, } 1 \text { patient } \\
\text { with NMO, } 12 \text { patients with optic } \\
\text { neuritis as a clinically isolated } \\
\text { syndrome }\end{array}$ & $\begin{array}{l}70 \% \text { of patients responded to plasma } \\
\text { exchange on measures of visual acuity; no } \\
\text { control group was included in the study }\end{array}$ & Hypofibrinogenaemia & 72 \\
\hline $\begin{array}{l}\text { IVIg } 400 \mathrm{mg} / \mathrm{kg} / \text { day } \times 5 \text { days }+\mathrm{IVIg} \\
400 \mathrm{mg} / \mathrm{kg} / \text { day once monthly for } \\
5 \text { months }(\mathrm{n}=23) \\
\text { No treatment }(\mathrm{n}=24)\end{array}$ & $\begin{array}{l}47 \text { patients with steroid-refractory } \\
\text { optic neuritis in MS }\end{array}$ & $\begin{array}{l}\text { A greater proportion of the IVIg-treated } \\
\text { patients demonstrated improvement in their } \\
\text { visual acuity compared with untreated control } \\
\text { participant }\end{array}$ & $\begin{array}{l}\text { Generalised headaches, infusion } \\
\text { reactions }\end{array}$ & 73 \\
\hline $\begin{array}{l}\text { Case report of } 23 \text { patients } \\
\text { treated with } 5 \text { cycles of plasma } \\
\text { exchange }\end{array}$ & $\begin{array}{l}23 \text { patients with steroid-unresponsive } \\
\text { optic neuritis associated with other } \\
\text { conditions (NMO, MS, CIS) in some } \\
\text { cases }\end{array}$ & $70 \%$ of patients showed some improvement & & 74 \\
\hline $\begin{array}{l}\text { IVMP } 250 \mathrm{mg} \text { every } 6 \mathrm{~h} \times 3 \text { days } \\
\text { +oral prednisone } 1 \mathrm{mg} / \\
\mathrm{kg} \times 11 \text { days+memantine }(\mathrm{n}=29) \\
\text { IVMP } 250 \mathrm{mg} \text { every } 6 \mathrm{~h} \times 3 \text { days } \\
\text { +oral prednisone } 1 \mathrm{mg} / \\
\mathrm{kg} \times 11 \text { days+placebo }(\mathrm{n}=31)\end{array}$ & $\begin{array}{l}60 \text { patients with first attack of } A O N \text {; } \\
\text { visual symptoms }<8 \text { days }\end{array}$ & $\begin{array}{l}\text { Greater RNFL thickness (overall, nasal, inferior, } \\
\text { and superior quadrants) in memantine-treated } \\
\text { group; no difference in visual function }\end{array}$ & None reported & 61 \\
\hline
\end{tabular}

ACTH, adrenocorticotropic hormone; AON, acute optic neuritis; EPO, erythropoietin; IVIg, intravenous immunoglobulin; IVMP, intravenous methylprednisolone; MS, multiple sclerosis; NMO, neuromyelitis optica; RNFL, retinal nerve fibre layer; RRMS, relapsing remitting MS.

axonal loss after retrobulbar AON. RNFL oedema as measured by OCT and SLP is far more common than noted on clinical examination. $^{25}$ Oedema is evident in approximately $82 \%$ of affected optic nerves and remains evident in at least one quadrant in the majority of patients by 12 weeks. ${ }^{25}$ On average, as measured by OCT, patients with AON lose $22 \mu \mathrm{m}$ more RNFL in their affected eye than in their unaffected eye in the 3-6 months after the inception of visual symptoms. ${ }^{26}$

To provide some perspective, the RNFL achieves a thickness of approximately $100 \mu \mathrm{m}$ by 10 years of age, and over the subsequent 60 years of life, healthy individuals can expect to lose approximately $10 \mu \mathrm{m}$ of thickness (corresponding to a rate of approximately $0.017 \%$ annually). After AON, RNFL loss is evident in the majority of individuals by 3 months, ${ }^{25}$ with nearly all patients showing segments of RNFL loss by 3 months. ${ }^{25} 2627$ RNFL thinning as measured by OCT has been observed to correlate with multiple visual metrics: high-contrast acuity, low-contrast acuity, visual field and colour vision. ${ }^{26} 2829$ For example, studies have demonstrated that a relevant loss of seven letters or more in low-contrast letter acuity predicts a corresponding reduction in the thickness of the RNFL in MS. ${ }^{28}$ The development and application of novel retinal segmentation algorithms for OCT have been used to sensitively and reproducibly measure anatomic compartments that reflect the extent of pathological and functional injury following AON. Specifically, the thickness of the ganglion cell and inner plexiform layers (GCL+IPL) facilitates measurement of ganglion cell loss after AON and correlates with visual function in affected individuals. $^{18} 22$

\section{MRI techniques}

In contrast to OCT, conventional MRI has demonstrated mixed correlations between optic nerve atrophy and visual function after AON. In some investigations, the use of short-echo fluid-attenuated inversion recovery and T1-weighted spin echo imaging has revealed a significant relationship among the degree of optic nerve atrophy and visual acuity, VEP amplitudes and latencies. ${ }^{30}{ }^{31}$ Across those studies that evaluated acute changes, the affected optic nerve was initially oedematous, with an increased mean cross-sectional area; later, optic atrophy developed. The administration of 'high-dose' intravenous methylprednisolone did not prevent or attenuate the subsequent development of optic nerve atrophy. ${ }^{32}$ 
Advanced MRI metrics, such as those derived with DTI and magnetisation transfer imaging ratios (MTR), have recently been adapted for orbital imaging. ${ }^{33}$ Traditionally, DTI and MTR methods have been employed infrequently for the purpose of orbital imaging, principally due to multiple and formidable technical challenges. In particular, the small size and mobile nature of the optic nerve, combined with confounding factors such as the signal intensity heterogeneity of the surrounding orbital structures (fat, bone and cerebrospinal fluid) mandate the application of rapid acquisition protocols in conjunction with high spatial resolution. ${ }^{34}$

In a non-conventional imaging study, MTR region of interest analysis showed a correlation with full-field VEP. ${ }^{35}$ In contrast, subsequent imaging analyses of the entire length of the optic nerve demonstrated a significant relationship with visual acuity but not with VEP latency changes. ${ }^{31}$ The MTR (a metric related to brain tissue integrity) in affected optic nerves declined slowly with a nadir of 240 days, a period that is longer than the standard interval for visual recovery. ${ }^{36}$ This may indicate that the window for treating AON may extend beyond the current clinical paradigm.

Recently, technical refinements in receiver coil characteristics, combined with high-field magnetic environments, have generated improved signal-to-noise ratios for DTI measures of axonal and myelin pathology in AON. Radial diffusivity has proven to be the most sensitive metric for differentiating the unaffected from affected optic nerves and correlates with visual recovery, electrophysiology (VEP latency and amplitude) and RNFL thickness (OCT). ${ }^{33} 37$ DTI, therefore, provides a novel, sensitive modality to complement RNFL structural injury in the evaluation of acute $\mathrm{ON}$ injury.

\section{Electrophysiology}

Electrophysiologic measures can reveal seminal features of axonal degeneration and inflammatory demyelination within the anterior visual system. Prolongation of the VEP P100 latency has long been used as a measure of conduction delay through the optic nerve and is a sensitive pathophysiological signature of demyelination. ${ }^{33} 38$ In contrast, a reduction in VEP amplitude can serve as a measure of axonal injury. As a summated response of multiple neuronal elements with differently oriented electrical dipoles, the full-field VEP is subject to significant limitations. First, the full-field VEP is dominated by the macular region and may not detect a significant fraction of $\mathrm{ON}$ cases with peripheral field loss. Next, full-field VEP may be hampered by changes in waveform architecture depending on the location of the optic nerve lesion or visual field loss.

Advancements in optics have introduced multifocal technology to VEP studies, and increased the ability to detect small changes within the central visual field. ${ }^{39}$ Full-field and mfVEP studies have demonstrated utility in predicting the magnitude of optic nerve injury and visual outcome in AON. ${ }^{39} 40$ The sensitivity of mfVEP may be enhanced further through the use of low-contrast pattern-reversal stimuli (analogous to the use of low-contrast letter acuity charts), allowing for the detection of mild residual injury or occult damage in the so-called 'unaffected' eye. ${ }^{16}$

The traditional ERG has had limited utility in the study of eyes in patients with MS. Nonetheless, the ONHC is a discrete late-response waveform of the ERG that can be used to detect electrophysiological changes in the context of acute AON. The ONHC is produced through a modified stimulus paradigm that includes global flash stimuli interleaved at specific intervals in the mfERG. The ONHC is thought to represent the transformation of slow membrane conduction to fast saltatory conduction, as axons traverse the lamina cribrosa and become myelinated. ${ }^{41}$ After AON, the ONHC waveforms are abolished and later recover, representing the transient effects of conduction block due to reversible demyelination. Frohman et $a l^{17}$ have demonstrated that eyes with previous optic neuritis in patients with MS exhibit changes or loss in the ONHC waveform that correlate with reduction in low-contrast letter acuity, RNFL thickness, visual field depression and amplitude loss and latency delay on mfVEP. Therefore, abnormalities of the ONHC response may provide a novel, additional pathophysiological signature of optic neuritis injury for acute treatment trials.

\section{Biomarkers}

Serum and plasma neurofilament levels, heavy (NfH) and light (NfL), are elevated in patients with $\mathrm{AON}$, independent of the inflammatory mechanism. ${ }^{19} \quad 21 \quad 42 \quad 43$ Supportive of a link between persistent vision loss and axonal degeneration, the levels of NfH and NfL have been observed to correlate with the extent of vision loss and the loss of retinal nerve fibre thickness following AON. Therefore, in addition to the aforementioned imaging and electrophysiological measures of optic nerve integrity and function, blood measures of $\mathrm{NfH}$ and $\mathrm{NfL}$ may provide additional information on neuronal loss and visual prognosis.

\section{Neuroimmunology}

AON lesions are rarely acquired for histopathological examination due to the limited nature of most injuries and the high probability for recovery. As a result, the composition of the inflammatory infiltrate in $\mathrm{AON}$ and the extent of glial and neuronal injury are inferred from that of acute CNS brain and spinal cord MS lesions. Demyelination in AON is presumed to be mediated by activation of endogenous microglia and a mixed inflammatory infiltrate consisting of $\mathrm{T}$ and $\mathrm{B}$ cells and peripheral macrophages. As in acute MS lesions, local expression of human leucocyte antigen (HLA) class II antigen, Th1 and Th17 proinflammatory $\mathrm{T}$ cells and axonal transections are evident. ${ }^{44}$ Tsoi et $a l^{45}$ noted pathological findings similar to those found in chronic active MS lesions in a 10-month-old ON lesions recovered at autopsy. These included myelin breakdown, infiltration and activation of macrophages and microglia, and gliosis. A detailed characterisation of the cellular infiltrate, measures of axonal transection, and local cytokine secretion were not performed.

The response of AON to interventions such as methylprednisolone, corticotrophin and PLEX implicate the combined action of cellular and humoral immune processes (table 2). The antiinflammatory and immunosuppressive actions of corticosteroid administration and hypothalamic-pituitary-adrenal axis modulation are quite complex and act at multiple levels to reduce the acute inflammatory response. ${ }^{46}$ At the cellular level, intravenous corticosteroids reduce the number of circulating monocytes and lymphocytes by modulating cell apoptosis. At the cell surface, they reduce the expression of adhesion molecules and matrix metalloproteinase expression to lessen blood-brain barrier permeability. In addition, corticosteroids alter the transcription of proinflammatory and anti-inflammatory cytokines expressed by peripheral blood mononuclear cells. In a recent study, the proinflammatory cytokines IL-17A, IL-6 and IL-23p19 were downregulated by the administration of intravenous corticosteroids in patients with MS, whereas anti-inflammatory cytokines IL-10, TGF- $\beta 1$ and IL-27p 28 were upregulated. ${ }^{47}$ In other investigations, two groups noted enhanced T regulatory cell (Treg) function after the administration of intravenous corticosteroid 
Table 2 Clinical measures of optic nerve function and structure

\begin{tabular}{|c|c|c|c|}
\hline $\begin{array}{l}\text { Structure/ } \\
\text { function }\end{array}$ & $\begin{array}{l}\text { Investigational } \\
\text { technique }\end{array}$ & Measurement & Change in optic neuritis affected eyes \\
\hline Function & $\begin{array}{l}\text { High-contrast visual } \\
\text { acuity }\end{array}$ & High-contrast resolution & Worsens acutely and improves over time ${ }^{4}$ \\
\hline Function & $\begin{array}{l}\text { Low-contrast visual } \\
\text { acuity }\end{array}$ & Low-contrast resolution & Worsens acutely and improves over time ${ }^{4}$ \\
\hline Function & Colour vision & Blue-yellow and red-green defects discrimination & $\begin{array}{l}\text { Abnormalities in colour discrimination that correlate with RNFL } \\
\text { thickness }^{29}\end{array}$ \\
\hline Function & ERG & Physiological integrity of cone and rod responses & $\begin{array}{l}\text { No difference in full field ERG. }{ }^{75} \text { Loss of OHNC of multifocal } \\
\text { ERG }^{17}\end{array}$ \\
\hline Function & VEP & Demyelination of the visual pathway & $\begin{array}{l}\text { Latency delay that improves in a fraction of affected individuals } \\
\text { over time }\end{array}$ \\
\hline Structure & Fundus photography & $\begin{array}{l}\text { Shows structure of inner surface of the eye (retina, optic disc, } \\
\text { macula and fundus) }\end{array}$ & Optic disc pallor, atrophy \\
\hline Structure & MRI & Optic nerve atrophy, tissue injury, blood-brain barrier breakdown & \\
\hline Structure & DTI & $\begin{array}{l}\text { Imaging of white matter damage and integrity of visual white } \\
\text { matter tracts }\end{array}$ & $\begin{array}{l}\text { Axonal and demyelinating injury to optic nerve and } \\
\text { postgeniculate white matter }\end{array}$ \\
\hline Structure & MTR & Myelination status and axonal content of the optic nerve & Demyelinating injury ${ }^{77}$ \\
\hline Structure & SLP & Measure RNFL thickness & $\begin{array}{l}\text { Shows a decrease in retardance in eyes with axonal injury } \\
\text { associated with visual field loss }\end{array}$ \\
\hline Structure & OCT & Measure RNFL thickness & $\begin{array}{l}\text { RNFL thickness decreases with MS and decreases further with } \\
\text { MS-related } \mathrm{ON}^{79} \text {; shows acute thickening due to edema }{ }^{25}\end{array}$ \\
\hline Function & mfERG & $\begin{array}{l}\text { Measures the transformation of slow membrane conduction in } \\
\text { unmyelinated ganglion cell axons to fast saltatory conduction in } \\
\text { myelinated axons }\end{array}$ & \\
\hline Function & ONHC of the mfERG & $\begin{array}{l}\text { Transient effects of conduction block due to reversible } \\
\text { demyelination }\end{array}$ & $\begin{array}{l}\text { Loss of this response signifies loss of myelination at the lamina } \\
\text { cribosa and disrupted transition from membrane to saltatory } \\
\text { transmission }^{17}\end{array}$ \\
\hline Function & mfVEP & Sensitive measure of axonal damage & Abnormal latency ${ }^{80}$ \\
\hline Function & Pupillometry & $\begin{array}{l}\text { Measurement of pupil diameter as an indicator of neural inhibitory } \\
\text { mechanisms }\end{array}$ & Pupillary reflex metrics impaired ${ }^{81}$ \\
\hline
\end{tabular}

treatment for acute MS relapse. ${ }^{48} 49$ These results suggest that corticosteroid therapy may restore impaired Treg function and reset the ratio of proinflammatory and anti-inflammatory cytokines after acute inflammatory demyelination. Although the potent anti-inflammatory effects of glucocorticoids have proven to be useful for increasing the rate of resolution of AON, it is possible that they have a negative impact on remyelination. In the cuprizone and experimental autoimmune encephalomyelitis animal models, high-dose glucocorticoids were found to inhibit remyelination, ${ }^{50} 51$ suggesting that there may be a need for AON therapies that can promote a more conducive environment for remyelination and neuronal recovery.

PLEX is presumed to mediate a therapeutic effect, at least in part, through the removal of pathogenic humoral and plasma factors. Indeed, PLEX has been shown to benefit both patients with idiopathic $\mathrm{AON}$ and those with NMO AON. ${ }^{11}{ }^{12}$ The utility of PLEX for the treatment of AON suggests that antibodies and/or proinflammatory serum components may facilitate optic nerve injury in AON.

\section{Novel anti-inflammatory actions of adrenocorticotropin hormone}

Recent studies have shown that $\alpha$-melanocyte stimulating hormone and adrenocorticotropic hormone (ACTH) have antiinflammatory effects in a number of models of acute CNS and ocular inflammation. ACTH is a member of the pro-opiomelanocortin-derived family of peptides called melanocortin peptides. Melanocortin peptides bind to G-protein coupled cell surface melanocortin receptors, of which five have been identified as melanocortin receptors 1-5 (MC1R-MC5R). ${ }^{52}$ The binding of ACTH to MC2R in the adrenal glands results in steroidogenesis. The other MCRs, however, are located throughout the body and are responsible for a variety of functions including direct, steroid-independent reduction of inflammation in the periphery and in the CNS (reviewed $i^{52}$ ). Melanocortin peptides also have a unique role in maintaining immunological homoeostasis in the eye; they have been reported to induce a functionally important population of $\mathrm{CD} 4+$ regulatory $\mathrm{T}$ cells in the experimental autoimmune uveitis animal model. ${ }^{53}$ Additionally, there are reports that melanocortin peptides can have neurotrophic effects. ${ }^{54}$ Clinical studies with advanced physiological measures will need to be performed to elucidate whether these properties are relevant in optic neuritis.

\section{Optic neuritis: alternative inflammatory injuries}

A fraction of patients with $\mathrm{AON}$ experience this syndrome in the context of NMO, a demyelinating disorder directed against the aquaporin-4 (AQP4) water channel, with predilection for the optic nerves and spinal cord. Compared with that of MS-associated ON, vision loss secondary to $\mathrm{ON}$ in the context of NMO is typically severe (acuity loss, visual field loss), ${ }^{55}$ with a lower predilection towards significant recovery and a greater amount of axonal degeneration as measured by OCT. $^{56}$ The 
greater magnitude in severity of the clinical syndrome, coupled with a worse prognosis for functional recovery in NMO-associated optic neuritis, may be a result of the targeted destruction of CNS and retinal astrocytes.

Among the broad diversity of CNS 'housekeeping' functions, astrocytes support neurotransmission and myelination, facilitate the clearance of extracellular potassium and water and facilitate nerve conduction. Further, astrocytes produce cytokines, such as platelet-derived growth factor, that stimulates the proliferation and differentiation of oligodendrocyte precursors into premyelinating oligodendrocytes. ${ }^{57}$ Consequently, the loss of astrocytes in NMO-associated optic neuritis may impair remyelination, an adaptive response to injury with trophic, protective, ion channel and energetic ramifications.

The depletion of astrocytes within the proximity of active CNS injury in NMO may also result in a protracted state of demyelination resulting in an inefficient method of axonal transmission by membrane rather than saltatory (nodal/paranodal) conduction. In the healthy $\mathrm{CNS}$, astrocytic processes drape themselves around the axons at myelin internodes and serve almost as a 'place-setting' for the orderly positioning of myelin wraps. When astrocyte loss is coupled with chronic demyelination, the intrinsic organisation of myelination and the clustering sodium channels at the nodes of Ranvier and paranodal regions is altered, and axonal conduction becomes inefficient. Interestingly, mice lacking glial fibrillary acidic protein (GFAP), an astrocyte-specific intermediate filament, demonstrate impaired optic nerve myelination, implicating the importance of astrocyte integrity in myelination. ${ }^{58}$

The much broader distribution of sodium channels necessary to reconstitute axonal conduction in the setting of chronic demyelination is commensurately associated with a greater energetic demand on intra-axonal mitochondria. ${ }^{59}$ The greater demand for ATP is at least partly related to the need to establish and maintain an altered equilibrium, secondary to multiple derangements in ion currents and altered channel characteristics. For example, newly synthesised sodium channels undergo pore closure, and thereby cessation of membrane depolarisation, in response to elevated temperature resulting in the clinical manifestation of Uhthoff's phenomenon. In addition, the accumulation of intra-axonal sodium and calcium can result in mitochondrial damage and bioenergetic failure through the production of reactive oxygen species. Potential players include inactivating sodium channels (eg, Nav1.6), sodium/calcium exchangers (eg, NCX), glutamate receptors (eg, GluR), acidsensing channels (eg, ASIC1), cation channels (eg, TRPM4) and voltage-dependent calcium channels (eg, VDCC). ${ }^{12} \quad 60$ The resulting intra-axonal energetic supply-demand mismatch can eventually provoke the liberation of excitatory amino acids, such as glutamate, culminating in irreversible axonal injury and neuronal demise, the presumed underpinning of chronic disability in AON. In support of this mechanism, a small trial using the $\mathrm{N}$-methyl-D-aspartate receptor antagonist, memantine, demonstrated less thinning of the RNFL in treated versus placebo participants. $^{61}$ Currently, the sodium channel-blocking agent, phenytoin, and the acid-sensing channel blocker, amiloride, are being used in clinical trials in AON. These clinical trials use RNFL thickness, as measured by OCT and SLP, as surrogate measures of neuroprotection.

Recent work has identified a small group of patients who present with AON but whose clinical course demonstrates atypical recurrent activity or dependency on immunosuppression. In 2003, Kidd et $a l^{62}$ described a cohort of patients who presented with painful, subacute optic neuropathy and responded promptly to treatment with systemic corticosteroids. These individuals relapsed rapidly on steroid withdrawal, and the condition was labelled chronic relapsing inflammatory optic neuropathy (CRION) to distinguish it from typical optic neuritis. Arndt et $a l^{63}$ described an additional cohort of patients with recurrent isolated optic neuritis (RION) who experienced repeated attacks of AON that resolved without treatment but resulted in progressive vision loss over time. No patients with CRION or RION presented with or developed MRI lesions consistent with MS, and testing for antibodies against AQP-4 revealed that only a small fraction of these individuals suffered from NMO. ${ }^{64}$ Patients with CRION or RION likely represent a small fraction of AON with a unique immunopathology. This could be due to targeting of a unique optic nerve-specific antigen or a deficient $\mathrm{T}$ regulatory response, or perhaps it is a consequence of a novel inflammatory response. The prospective evaluation of patients with acute CRION and RION with immunological measures, OCT and electrophysiology will be critical for identifying novel diagnostic and therapeutic approaches.

\section{New therapies for the treatment of acute demyelinating injury}

The array of MS therapies has increased rapidly over the past decade. Therapies approved in the 1990s, $\beta$-interferon and glatiramer acetate, have been joined by new treatments with novel mechanisms of action: inhibition of leucocyte adhesion (natalizumab); interference with S1P-mediated lymph node egress (fingolimod); interference with lymphocyte replication (teriflunomide) and activation of the oxidative stress response pathway (dimethyl fumarate). The ability of these therapies to minimise injury or promote recovery after acute demyelination, however, has rarely been evaluated. Based on their rapid onset and CNS penetration, some of these newer MS therapies may offer promise in limiting vision loss and facilitating recovery after AON. A single dose of natalizumab, administered soon after the onset of an MS relapse, did not hasten clinical recovery but decreased Gd-enhancing lesion volume. ${ }^{65}$ The lack of a demonstrable change in the rate of clinical recovery may have been due to the variety of clinical presentations, the insensitivity of the clinical measure (Expanded Disability Status Scale) and the lack of sensitive paraclinical tools to assess the impact on anatomic and physiological changes. Indeed, fingolimod recently has shown efficacy in ameliorating $\mathrm{AON}$ in the experimental autoimmune optic neuritis animal model when administered during the effector phase of the disease. ${ }^{66} \mathrm{~A}$ similar effect has been noted using dimethyl fumarate after the onset of CNS inflammation in the experimental autoimmune encephalomyelitis model. ${ }^{67}$ The potential neuroprotective action of fingolimod and dimethyl fumarate in these animal models suggests that these agents may be ideally suited for the acute treatment of AON.

There are now therapeutic approaches with the capability of inducing remyelination in experimental animal models. In a toxin-induced rodent model of demyelination, an antibody against LINGO1, a CNS protein that acts as a negative regulator of oligodendrocyte precursor differentiation, promoted CNS remyelination by creating a microenvironment conducive to oligodendrocyte differentiation. ${ }^{68}$ Anti-LINGO1 monoclonal antibody has been humanised and is being tested in early clinical trials of patients with MS. Reparative agents such as anti-LINGO1 may offer a unique avenue for facilitating the restoration of visual function in AON.

Advancements in the understanding of the mechanisms underlying acute CNS demyelination, novel developments in the 
ability to measure axonal and myelin injury, treatments with novel anti-inflammatory and immunomodulatory mechanisms, and an unmet therapeutic need warrant a renewed investigation of the treatment of AON. Clinical research on AON with both established and new agents can provide information on multiple complementary outcomes: clinical recovery, tissue preservation and remyelination. The resulting data on visual acuity (high and low contrast), visual fields, colour vision, peripapillary RNFL thickness, GCL+IPL thickness, ONHC responses in mfERG, mfVEP and DTI will provide an elaborate framework in which to decipher a specific agent's effect on inflammation, axonal integrity, neuronal survival, oligodendrocyte injury and remyelination.

\section{Clinical trials for AON therapy}

Given the significant visual improvement (median recovery 20/ 16) observed in the ONTT placebo group, ${ }^{5}$ future clinical trials to evaluate new AON treatments will likely require significant patient numbers to ensure adequate powering. As a result, the need for substantial patient enrolment may dissuade the assessment of certain compounds with potentially moderate clinical effects. Therefore, the analysis of retinal architecture by OCT and related methods may prove to be a valuable surrogate for neuroprotection after acute inflammatory injury. Indeed,
Henderson et $a l^{27}$ have estimated sample sizes for clinical trials of therapeutic agents in AON, when using OCT as the outcome measure, and demonstrated that as few as 75 patients per treatment arm are needed to provide $90 \%$ power for a modest $40 \%$ effect size. The increased sensitivity of GCL+IPL measurement may reduce enrolment requirements further. ${ }^{22} \mathrm{~A}$ positive result from a smaller OCT trial may provide the needed impetus to investigate the impact on clinical outcomes in a larger phase 3 trial.

\section{Future directions}

Advances in our understanding of demyelinating injury and the development of novel structural and physiological metrics of optic nerve integrity provide a promising environment for future translational and clinical research in AON (figure 1). In addition, the close relationship between idiopathic AON and other CNS demyelinating lesions allows the results of $\mathrm{AON}$ studies to immediately impact our understanding of MS pathophysiology and treatment. Using sensitive metrics such as OCT, ONHC, mfVEPs and DTI, future investigations may simultaneously address questions regarding the mechanism and timing of oligodendrocyte and RGC injury, the beneficial effects of immunomodulatory and neuroprotective therapies, and the efficacy of restorative interventions.

\section{Potential Therapeutic Targets in ON}

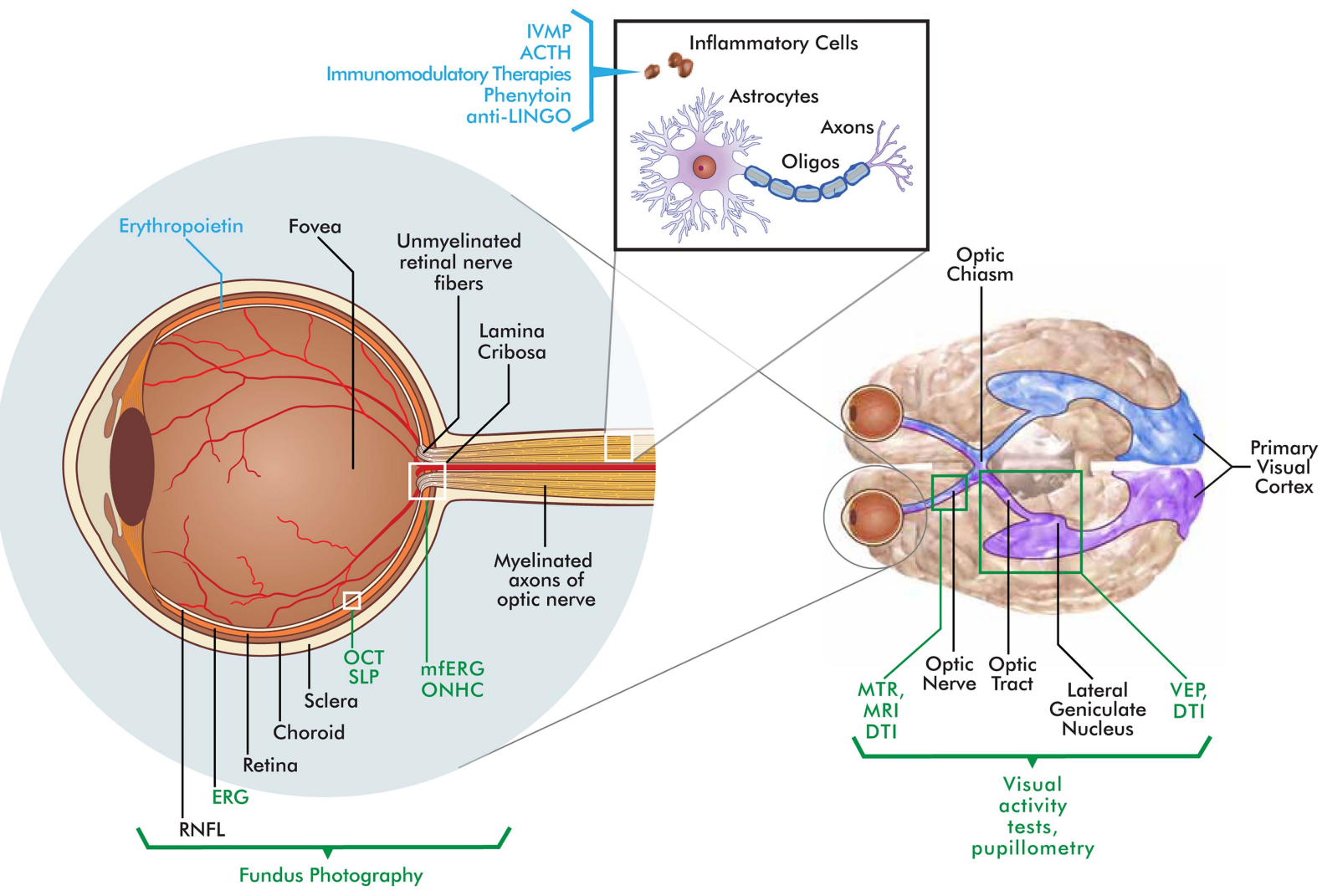

\section{Measurements of structure/function}

Figure 1 Schematic of the retina, optic nerve and postchiasmal afferent visual system. Potential therapeutic targets (blue text) and measures of visual function (green text) are illustrated above and below the diagram, respectively (RNFL, retinal nerve fibre layer; ERG, electroretinogram; OCT, optical coherence tomography; ONHC, optic nerve head component; SLP, scanning laster polarimetry; VEP, visual evoked potential; DTI, diffusion tensor imaging; MTR, magnetisation transfer imaging ratios). 
With these objectives in mind, a future AON treatment trial need only utilise a few sites to enrol a sufficient number of participants to evaluate multiple effects of a therapeutic agent. For example, a recent two-institution clinical trial (clinicaltrials.gov; NCT01838174) has been designed to compare the antiinflammatory, neuroprotective and restorative effects of ACTH and methylprednisolone using OCT and electrophysiology. Using OCT of the peripapillary RNFL and macula, the trial will compare RNFL loss and GCL+IPL thinning to compare the neuroprotective effects of these compounds on axonal and RGC survival. In addition, OCT will be used to examine whether the differential anti-inflammatory effects of ACTH and methylprednisolone affect the rate of resolution of optic nerve head oedema and the timing of RNFL thinning and RGC loss. Sensitive electrophysiological metrics such as mfVEPs and the ONHC of the mfERG will be used in concert with OCT to evaluate the extent of and recovery from demyelinating injury.

While novel in integrating many new approaches for the evaluation of optic nerve integrity and function, this study highlights many of the unresolved questions facing the optimal design of clinical trials in AON. What is the optimal window for the enrolment and institution of therapy in AON? Small trials with encouraging results on neuroprotection suggest the window may be small (8-10 days). Ultimately, however, the therapeutic window may vary based on the mechanism of action of the agent (ie, anti-inflammatory or neuroprotective), method of administration (oral, intravenous, retrobulbar) and pharmacodynamics (time to therapeutic level/effect in target tissue). What is the optimal outcome measure? Is it anatomic (RNFL thickness), electrophysiological (mfVEP, ONHC) or functional (VF, LCVA)? As noted previously, each metric has merits and limitations. In the short term, a pragmatic approach may be best. Sensitive measures of axonal, glial or neuronal injury such as OCT and mfVEP may be ideal to identify treatment effects in small cohorts. Afterwards, compounds with significant results can be moved forward into larger trials designed to document clinical improvement in AON and other demyelinating injuries. The data acquired from this and other ongoing AON trials will likely provide the foundation for using AON as a paradigm disorder for clinical and translational studies of demyelinating disease.

\footnotetext{
Author affiliations

${ }^{1}$ Departments of Neurology and Ophthalmology, University of Colorado, Denver, Colorado, USA

${ }^{2}$ Department of Medical Affairs, Questcor Pharmaceuticals, Inc., Hayward, California, USA

${ }^{3}$ Departments of Clinical Neurosciences and Surgery, University of Calgary, Hotchkiss Brain Institute, Alberta, Canada

${ }^{4}$ Neuro-Ophthalmology Service, Wills Eye Institute, Thomas Jefferson University

Medical College, Philadelphia, Pennsylvania, USA

${ }^{5}$ Minneapolis Clinic of Neurology, Minneapolis, Minnesota, USA

${ }^{6}$ Department of Neurology, Division of Neuro-Ophthalmology, NYU Langone Medical Center, New York, USA

${ }^{7}$ Perelman School of Medicine, University of Pennsylvania, Philadelphia,

Pennsylvania, USA

${ }^{8}$ Rockefeller University and Memorial Sloan-Kettering Hospital, Weill Cornell Medical College, New York, USA

${ }^{9}$ Department of Neurology, Harbor-University of California Los Angeles Medical

Center, Torrance, California, USA

${ }^{10}$ Department of Ophthalmology, Boston University School of Medicine, Boston,

Massachusetts, USA

${ }^{11}$ College of Nursing at the University of Arizona, Tucson, Arizona, USA

${ }^{12}$ Departments of Neurology \& Neurotherapeutics, University of Texas Southwestern Medical Center, Dallas, Texas, USA

${ }^{13}$ Departments of Ophthalmology, University of Texas Southwestern Medical Center Dallas, Texas, USA
}

Acknowledgements The authors thank MedVal Scientific Information Services, LLC, for editorial assistance.

Contributors JLB, EMF - conceived, designed and drafted the review. MN, FC, RCS, JCC, SLG, LJB, CEM, TV, MM, MLM, AWT, TWP, TF - performed critical revisions of the manuscript for important intellectual content.

Funding Editorial assistance was funded by Questcor Pharmaceuticals, Inc.

Competing interests All authors attended a scientific advisory board hosted by Questcor Pharmaceuticals, Inc. JLB receives grants from the Guthy Jackson Research Foundation and the NIH (EY022936); serves as a consultant for Novartis Pharmaceuticals, Alnaylam Pharmaceuticals, Medlmmune, Chugai Pharmaceuticals, EMD Serono, Abbott Pharmaceuticals, Genentech, Genzyme and Questcor

Pharmaceuticals; receives licence royalties for a patent re Compositions and Methods for the Treatment of Neuromyelitis Optica; and serves on the editorial boards of the Multiple Sclerosis Journal and Journal of Neuro-ophthalmology. MN employee of Questcor Pharmaceuticals, Inc. FC receives grants from the Multiple Sclerosis Society of Canada, speaker fees from EMD Serono and serves as a consultant for Novartis Pharmaceuticals. RCS serves as a consultant for Biogen-Idec, EMD Serono, Teva Neuroscience, Lundbeck, Pfizer, Thrombogenics, Sanofi-Aventis, Novartis Pharmaceuticals, BioClinica, Covance, Glaxo-Smith-Kline, Questcor, Heidelberg Engineering, Merck, United States Department of Defense, and the Food And Drug Administration; receives speaker honoraria from Biogen-Idec, EMD Serono, Teva Neuroscience, Lundbeck, Pfizer, Novartis Pharmaceuticals, Sanofi-Aventis and Questcor. JCC receives research support from Novartis Pharmaceuticals, Biogen-Idec and Roche; receives speaking fees from Acorda Therapeutics, Novartis

Pharmaceuticals, Biogen-Idec, EMD Serono, Genzyme, Bayer Healthcare, Acorda Therapeutics, Questcor and Teva Neuroscience; and receives consultant fees from Novartis Therapeutics, Biogen-Idec, Genzyme, Acorda Therapeutics and Questcor. SLG serves as a consultant for Vaccinex and Biogen-Idec. LJB receives consulting fees from Biogen-Idec, Questcor and Vaccinex. CEM serves as a consultant for Biogen-Idec, Teva Neuroscience, Bayer Healthcare, EMD-Serono, Questcor, Novartis, Genzyme, Roche and Genentech. TV receives speaker honoraria and consulting fees from Biogen, Teva Neuroscience, Novartis, Genzyme, EMD Serono and Questcor. MM receives research support from Novartis Pharmaceuticals. MLM receives speaker honoraria from Biogen-Idec and Novartis Pharmaceuticals and research support from Acorda Therapeutics. AWT receives consulting fees from Palatin Technologies. TF receives speaker honoraria and consulting fees from Biogen-Idec, Teva Neuroscience, Novartis Pharmaceuticals, Genzyme and Acorda Therapeutics. EMF receives speaker honoraria and consulting fees from Biogen-ldec, Teva Neuroscience, Novartis Pharmaceuticals, Genzyme and Acorda Therapeutics.

Provenance and peer review Not commissioned; externally peer reviewed.

Open Access This is an Open Access article distributed in accordance with the Creative Commons Attribution Non Commercial (CC BY-NC 4.0) license, which permits others to distribute, remix, adapt, build upon this work non-commercially, and license their derivative works on different terms, provided the original work is properly cited and the use is non-commercial. See: http://creativecommons.org/ licenses/by-nc/4.0/

\section{REFERENCES}

1 Miller H, Newell DJ, Ridley A. Multiple sclerosis. Treatment of acute exacerbations with corticotrophin (A.C.T.H.). Lancet 1961;2:1120-2.

2 Rawson MD, Liversedge LA. Treatment of retrobulbar neuritis with corticotrophin. Lancet 1969:2:222.

3 Gal RL, Vedula SS, Beck R. Corticosteroids for treating optic neuritis. Cochrane Database Syst Rev 2012;4:CD001430.

4 Beck RW, Cleary PA, Anderson MM Jr, et al. A randomized, controlled trial of corticosteroids in the treatment of acute optic neuritis. The Optic Neuritis Study Group. N Engl J Med 1992;326:581-8.

5 Beck RW, Cleary PA. Optic neuritis treatment trial. One-year follow-up results. Arch Ophthalmol 1993;111:773-5

6 Hickman SJ, Kapoor R, Jones SJ, et al. Corticosteroids do not prevent optic nerve atrophy following optic neuritis. J Neurol Neurosurg Psychiatry 2003;74:1139-41.

7 Beck RW, Cleary PA, Trobe JD, et al. The effect of corticosteroids for acute optic neuritis on the subsequent development of multiple sclerosis. The Optic Neuritis Study Group. N Engl J Med 1993;329:1764-9

8 Goodin DS. Perils and pitfalls in the interpretation of clinical trials: a reflection on the recent experience in multiple sclerosis. Neuroepidemiology 1999;18:53-63.

9 Roed HG, Langkilde A, Sellebjerg F, et al. A double-blind, randomized trial of IV immunoglobulin treatment in acute optic neuritis. Neurology 2005;64:804-10.

10 Noseworthy JH, O'Brien PC, Petterson TM, et al. A randomized trial of intravenous immunoglobulin in inflammatory demyelinating optic neuritis. Neurology 2001;56:1514-22.

11 Ruprecht $\mathrm{K}$, Klinker $\mathrm{E}$, Dintelmann $\mathrm{T}$, et al. Plasma exchange for severe optic neuritis: treatment of 10 patients. Neurology 2004;63:1081-3. 
12 Schattling B, Steinbach K, Thies E, et al. TRPM4 cation channel mediates axonal and neuronal degeneration in experimental autoimmune encephalomyelitis and multiple sclerosis. Nat Med 2012;18:1805-11.

13 Diem R, Sättler MB, Merkler D, et al. Combined therapy with methylprednisolone and erythropoietin in a model of multiple sclerosis. Brain 2005;128:375-85.

14 Suhs KW, Hein K, Sattler MB, et al. A randomized, double-blind, phase 2 study of erythropoietin in optic neuritis. Ann Neurol 2012;72:199-210.

15 Blazek P, Davis SL, Greenberg BM, et al. Objective characterization of the relative afferent pupillary defect in MS. J Neurol Sci 2012;323:193-200.

16 Frohman AR, Schnurman Z, Conger A, et al. Multifocal visual evokedpotentials are influenced by variable contrast stimulation in MS. Neurology 2012;79:797-801.

17 Frohman TC, Beh SC, Saidha S, et al. Optic nerve head component responses of the multifocal electroretinogram in MS. Neurology 2013;81:545-51.

18 Ratchford JN, Saidha S, Sotirchos ES, et al. Active MS is associated with accelerated retinal ganglion cell/inner plexiform layer thinning. Neurology 2013;80:47-54.

19 Petzold A, Plant GT. The diagnostic and prognostic value of neurofilament heavy chain levels in immune-mediated optic neuropathies. Mult Scler Int 2012;2012:217802.

20 Saidha S, Syc SB, Ibrahim MA, et al. Primary retinal pathology in multiple sclerosis as detected by optical coherence tomography. Brain 2011;134:518-33.

21 Petzold A, Rejdak K, Plant GT. Axonal degeneration and inflammation in acute optic neuritis. J Neurol Neurosurg Psychiatry 2004;75:1178-80.

22 Chatziralli IP, Moschos MM, Brouzas D, et al. Evaluation of retinal nerve fibre layer thickness and visual evoked potentials in optic neuritis associated with multiple sclerosis. Clin Exp Optom 2012;95:223-8.

23 Frohman EM, Fujimoto JG, Frohman TC, et al. Optical coherence tomography: a window into the mechanisms of multiple sclerosis. Nat Clin Pract Neurol 2008:4:664-75.

24 Zaveri MS, Conger A, Salter A, et al. Retinal imaging by laser polarimetry and optical coherence tomography evidence of axonal degeneration in multiple sclerosis. Arch Neurol 2008;65:924-8

25 Kupersmith MJ, Mandel G, Anderson S, et al. Baseline, one and three month changes in the peripapillary retinal nerve fiber layer in acute optic neuritis: relation to baseline vision and MRI. J Neurol Sci 2011;308:117-23.

26 Costello F, Coupland S, Hodge W, et al. Quantifying axonal loss after optic neuritis with optical coherence tomography. Ann Neurol 2006;59:963-9.

27 Henderson $A P$, Altmann DR, Trip AS, et al. A serial study of retinal changes following optic neuritis with sample size estimates for acute neuroprotection trials. Brain 2010;133:2592-602.

28 Fisher JB, Jacobs DA, Markowitz CE, et al. Relation of visual function to retinal nerve fiber layer thickness in multiple sclerosis. Ophthalmology 2006;113:324-32.

29 Villoslada P, Cuneo A, Gelfand J, et al. Color vision is strongly associated with retinal thinning in multiple sclerosis. Mult Scler 2012;18:991-9.

30 Hickman SJ, Toosy AT, Miszkiel KA, et al. Visual recovery following acute optic neuritis - a clinical, electrophysiological and magnetic resonance imaging study. J Neurol 2004;251:996-1005.

31 Inglese M, Ghezzi A, Bianchi S, et al. Irreversible disability and tissue loss in multiple sclerosis: a conventional and magnetization transfer magnetic resonance imaging study of the optic nerves. Arch Neurol 2002;59:250-55.

32 Hickman SJ, Coulon O, Parker GJ, et al. Application of a B-spline active surface technique to the measurement of cervical cord volume in multiple sclerosis from three-dimensional MR images. J Magn Reson Imaging 2003;18:368-71.

33 Naismith RT, Xu J, Tutlam NT, et al. Disability in optic neuritis correlates with diffusion tensor-derived directional diffusivities. Neurology 2009; 72:589-94.

34 Glisson CC, Galetta SL. Nonconventional optic nerve imaging in multiple sclerosis. Neuroimaging Clin N Am 2009;19:71-9.

35 Thorpe J, Barker G, Jones S, et al. Magnetisation transfer ratios and transverse magnetisation decay curves in optic neuritis: correlation with clinical findings and electrophysiology. J Neurol Neurosurg Psychiatry 1995;59:487-92.

36 Hickman SJ, Toosy AT, Jones SJ, et al. Serial magnetization transfer imaging in acute optic neuritis. Brain 2004;127:692-700.

37 Naismith RT, Xu J, Tutlam NT, et al. Radial diffusivity in remote optic neuritis discriminates visual outcomes. Neurology 2010;74:1702-10.

38 Gronseth GS, Ashman EJ. Practice parameter: the usefulness of evoked potentials in identifying clinically silent lesions in patients with suspected multiple sclerosis (an evidence-based review): report of the Quality Standards Subcommittee of the American Academy of Neurology. Neurology 2000;54:1720-5.

39 Klistorner A, Arvind $H$, Nguyen T, et al. Multifocal VEP and OCT in optic neuritis: a topographical study of the structure-function relationship. Doc Ophthalmol 2009;118:129-37.

40 Henderson AP, Altmann DR, Trip SA, et al. Early factors associated with axonal loss after optic neuritis. Ann Neurol 2011;70:955-63.

41 Sutter EE, Bearse MA Jr. The optic nerve head component of the human ERG. Vision Res 1999:39:419-36.

42 Modvig S, Degn M, Horwitz $\mathrm{H}$, et al. Relationship between cerebrospinal fluid biomarkers for inflammation, demyelination and neurodegeneration in acute optic neuritis. PLOS ONE 2013;8:e77163.
43 Pasol J, Feuer W, Yang C, et al. Phosphorylated neurofilament heavy chain correlations to visual function, optical coherence tomography, and treatment. Mult Scler Int 2010;2010:542691.

44 Frischer JM, Bramow S, Dal-Bianco $A$, et al. The relation between inflammation and neurodegeneration in multiple sclerosis brains. Brain 2009;132:1175-89.

45 Tsoi VL, Hill KE, Carlson NG, et al. Immunohistochemical evidence of inducible nitric oxide synthase and nitrotyrosine in a case of clinically isolated optic neuritis. J Neuroophthalmol 2006;26:87-94.

46 Tischner D, Reichardt HM. Glucocorticoids in the control of neuroinflammation. $\mathrm{Mol}$ Cell Endocrinol 2007;275:62-70.

47 Muls N, Jnaoui K, Dang HA, et al. Upregulation of IL-17, but not of IL-9, in circulating cells of CIS and relapsing MS patients. Impact of corticosteroid therapy on the cytokine network. J Neuroimmunol 2012;243:73-80.

$48 \mathrm{Xu} \mathrm{L}, \mathrm{Xu} \mathrm{Z}, \mathrm{Xu} \mathrm{M}$. Glucocorticoid treatment restores the impaired suppressive function of regulatory $T$ cells in patients with relapsing-remitting multiple sclerosis. Clin Exp Immunol 2009;158:26-30.

49 Braitch M, Harikrishnan S, Robins RA, et al. Glucocorticoids increase CD4CD25 cell percentage and Foxp3 expression in patients with multiple sclerosis. Acta Neurol Scand 2009;119:239-45.

50 Clarner T, Parabucki A, Beyer C, et al. Corticosteroids impair remyelination in the corpus callosum of cuprizone-treated mice. J Neuroendocrinol 2011:23:601-11.

51 Diem R, Demmer I, Boretius $S$, et al. Autoimmune optic neuritis in the common marmoset monkey: comparison of visual evoked potentials with MRI and histopathology. Invest Ophthalmol Vis Sci 2008;49:3707-14.

52 Catania A, Gatti S, Colombo G, et al. Targeting melanocortin receptors as a nove strategy to control inflammation. Pharmacol Rev 2004;56:1-29.

53 Lee DJ, Taylor AW. Following EAU recovery there is an associated MC5r-dependent APC induction of regulatory immunity in the spleen. Invest Ophthalmol Vis Sci 2011;52:8862-7

54 Lindqvist N, Napankangas U, Lindblom J, et al. Proopiomelanocortin and melanocortin receptors in the adult rat retino-tectal system and their regulation after optic nerve transection. Eur J Pharmacol 2003;482:85-94.

55 Merle $\mathrm{H}$, Olindo $\mathrm{S}$, Bonnan $\mathrm{M}$, et al. Natural history of the visual impairment of relapsing neuromyelitis optica. Ophthalmology 2007;114:810-15.

56 Naismith RT, Tutlam NT, Xu J, et al. Optical coherence tomography differs in neuromyelitis optica compared with multiple sclerosis. Neurology 2009;72:1077-82.

57 Raff MC, Lillien LE, Richardson WD, et al. Platelet-derived growth factor from astrocytes drives the clock that times oligodendrocyte development in culture. Nature 1988;333:562-5.

58 Liedtke W, Edelmann W, Bieri PL, et al. GFAP is necessary for the integrity of CNS white matter architecture and long-term maintenance of myelination. Neuron 1996:17:607-15.

59 Fischer MT, Sharma R, Lim JL, et al. NADPH oxidase expression in active multiple sclerosis lesions in relation to oxidative tissue damage and mitochondrial injury. Brain 2012;135:886-99.

60 Trapp BD, Stys PK. Virtual hypoxia and chronic necrosis of demyelinated axons in multiple sclerosis. Lancet Neurol 2009;8:280-91.

61 Esfahani MR, Harandi ZA, Movasat M, et al. Memantine for axonal loss of optic neuritis. Graefes Arch Clin Exp Ophthalmol 2012;250:863-9.

62 Kidd D, Burton B, Plant GT, et al. Chronic relapsing inflammatory optic neuropathy (CRION). Brain 2003;126:276-84.

63 Arndt C, Labauge $\mathrm{P}$, Speeg-Schatz $\mathrm{C}$, et al. Recurrent inflammatory optic neuropathy. J Fr Ophtalmol 2008;31:363-7.

64 Petzold A, Pittock S, Lennon V, et al. Neuromyelitis optica-lgG (aquaporin-4) autoantibodies in immune mediated optic neuritis. J Neurol Neurosurg Psychiatry 2010;81:109-11

65 O'Connor PW, Goodman A, Willmer-Hulme AJ, et al. Randomized multicenter trial of natalizumab in acute MS relapses: clinical and MRI effects. Neurology 2004;62:2038-43.

66 An X, Kezuka T, Usui Y, et al. Suppression of experimental autoimmune optic neuritis by the novel agent fingolimod. I Neuroophthalmol 2013;33:143-8

67 Linker RA, Lee D-H, Ryan S, et al. Fumaric acid esters exert neuroprotective effects in neuroinflammation via activation of the Nrf2 antioxidant pathway. Brain 2011;134:678-92.

68 Mi S, Miller RH, Tang W, et al. Promotion of central nervous system remyelination by induced differentiation of oligodendrocyte precursor cells. Ann Neurol 2009:65:304-15.

69 Rawson MD, Liversedge LA, Goldfarb G. Treatment of acute retrobulbar neuritis with corticotrophin. Lancet 1966;2:1044-6.

70 Bowden AN, Bowden PM, Friedmann Al, et al. A trial of corticotrophin gelatin injection in acute optic neuritis. J Neurol Neurosurg Psychiatry 1974;37:869-73.

71 Kapoor R, Miller DH, Jones SJ, et al. Effects of intravenous methylprednisolone on outcome in MRI-based prognostic subgroups in acute optic neuritis. Neurology 1998:50:230-7

72 Achiron A. Winning combination: the additive/synergistic benefits of IVIg in corticosteroid refractory optic neuritis. Eur J Neurol 2008;15:1145.

73 Tselis A, Perumal J, Caon C, et al. Treatment of corticosteroid refractory optic neuritis in multiple sclerosis patients with intravenous immunoglobulin. Eur J Neurol 2008;15:1163-7. 


\section{Multiple sclerosis}

74 Roesner S, Appel R, Gbadamosi J, et al. Treatment of steroid-unresponsive optic neuritis with plasma exchange. Acta Neurol Scand 2012;126:103-8.

75 Fraser CL, Holder GE. Electroretinogram findings in unilateral optic neuritis. Doc Ophthalmol 2011:123:173-8.

76 Reich DS, Smith SA, Gordon-Lipkin EM, et al. Damage to the optic radiation in multiple sclerosis is associated with retinal injury and visual disability. Arch Neurol 2009;66:998-1006.

77 Trip SA, Wheeler-Kingshott C, Jones SJ, et al. Optic nerve diffusion tensor imaging in optic neuritis. Neuroimage 2006;30:498-505.
78 Kupersmith MJ, Kardon R, Durbin M, et al. Scanning laser polarimetry reveals status of RNFL integrity in eyes with optic nerve head swelling by OCT. Invest Ophthalmol Vis Sci 2012;53:1962-70.

79 Pulicken M, Gordon-Lipkin E, Balcer L, et al. Optical coherence tomography and disease subtype in multiple sclerosis. Neurology 2007;69:2085-92.

80 Fraser CL, Klistorner A, Graham SL, et al. Multifocal visual evoked potential analysis of inflammatory or demyelinating optic neuritis. Ophthalmology 2006;113:315-23.

81 Salter AR, Conger A, Frohman TC, et al. Retinal architecture predicts pupillary reflex metrics in MS. Mult Scler 2009;15:479-86. 